\title{
APLIKASI PENGOLAHAN CITRA DIGITAL UNTUK PENDETEKSI JAWABAN PADA LEMBAR JAWABAN KOMPUTER MENGGUNAKAN ALGORITMA SOBEL (STUDI KASUS SMP NEGERI 2 KOTA BENGKULU)
}

\author{
Asahar Johar ${ }^{1}$, Desi Andreswari², Gita Triyana ${ }^{3}$ \\ ${ }^{1,2,3}$ Program StudiTeknikInformatika, FakultasTeknik, Universitas Bengkulu \\ Jl. W.R. SupratmanKandangLimun Bengkulu 38371 A \\ Telp. (0736) 344087, $21170-227$ \\ 1 asahar.johar@yahoo.com, ${ }^{2}$ dezieandrez@yahoo.co.id, ${ }^{3}$ triyanagita@yahoo.com
}

\begin{abstract}
ABSTRAK
Lembar Jawaban Komputer (LJK) merupakan lembar jawaban yang digunakan untuk melakukan ujian secara tertulis. Pemeriksaan LJK harus menggunakan alat scanner khusus, mengingat harga scanner sangat mahal maka penulis bermaksud untuk membangun aplikasi pengolahan citra digital untuk mendeteksi jawaban pada lembar jawaban komputer menggunakan Algoritma Sobel. Metode Sobel merupakan pengembangan metode Robert dengan menggunakan filter HPF (High Pass Filter) yang diberi satu angka nol penyangga. Kelebihan dari metode Sobel ini adalah kemampuan untuk mengurangi noise sebelum melakukan perhitungan deteksi tepi. Penulis mengubah data citra LJK menjadi bentuk deteksi tepi sobel untuk mempermudah mendeteksi jawaban pada LJK. Hasil deteksi jawaban pada LJK akan dilakukan pencocokkan dengan data kunci jawaban untuk memperoleh skor nilai. Selain itu laporan nilai siswa dapat ditampilkan secara otomatis menggunakan Fastreport. Aplikasi ini dibangun menggunakan bahasa pemrograman Delphi.dan metode pengembangan sistem pada aplikasi ini menggunakan metodeWaterfall.Sedangkan metode untuk perancangan sistem, penulis menggunakanUnified Modeling Language (UML). Hasil akhir dari penelitian ini adalah terciptanya suatu aplikasi pendeteksi jawaban pada LJK yang dapatdigunakanmelakukan pengoreksian LJK.
\end{abstract}

Kata kunci: Pengolahan Citra Digital, Sobel, LJK, Deteksi LJK.

\section{PENDAHULUAN}

\section{A. Latar Belakang}

Pendidikan merupakan sebuah proses kegiatan yang disengaja atas input peserta didik untuk menimbulkan suatu hasil yang diinginkan sesuai tujuan yang ditetapkan. Sebagai sebuah proses yang disengaja maka pendidikan harus dievaluasi hasilnya untuk melihat apakah hasil yang dicapai telah sesuai dengan tujuan yang diinginkan dan apakah proses yang dilakukan efektif untuk mencapai hasil yang diinginkan. Evaluasi artinya penilaian terhadap tingkat keberhasilan peserta didik mencapai tujuan yang telah ditetapkan dalam sebuah program (Widoyoko ,2009).

Sesuai dengan Undang-UndangNomor 20 Tahun 2003 Pasal 57 (ayat 1), evaluasi dalam pendidikan sangatlah penting sebagai pengendalian mutu pendidikan secara nasional sebagai bentuk akuntabilitas penyelenggara pendidikan kepada pihakpihak yang berkepentingan. Hasil yang diperoleh dari evaluasi dapat dijadikan umpan balik bagi guru dalam memperbaiki dan menyempurnakan program dan kegiatan pembelajaran. Undang-undang Nomor 20 Tahun 2003 Pasal 57 (ayat 2) menyatakan bahwa evaluasi dilakukan terhadap peserta didik, lembaga dan program pendidikan jalur formal dan nonformal untuksemua jenjang, satuan dan jenis pendidikan. Penilaian hasil belajar peserta didik harus dilakukan secara berkesinambungan untuk memantau proses, kemajuan, dan perbaikan hasil dalam bentuk Try Out Ujian Nasional (UN) yang biasanya dilakukan dengan melakukan pengisian pada Lembar Jawaban Komputer.

Disamping itu Software Pemeriksa Ujian diper lukan oleh sekolah mulai dari tingkat sekolah dasar hingga sekolah menengah. Kebutuhan tersebut tidak terlepas dari keinginan pihak sekolah dalam menyiapkan anak didiknya untuk menghadapi Ujian Nasional. Sudah bukan rahasia lagi bahwa Ujian Nasional telah menjadi momok tersendiri bagi peserta didik karena masih tingginya tingkat ketidaklulusan. Oleh karena itulah diperlukan latihan dalam mengisi lembar jawaban komputer.

Akan tetapi mengingat mahalnya harga dari alat scan yang khusus digunakan untuk memeriksa LJK tersebut yang mencapai harga belasan hingga puluhan juta rupiah, tentu hal tersebut sangat memberatkan pihak sekolah untuk membelinya, terlebih lagi jika sekolah tersebut tidak mendapatkan bantuan dari pemerintah. Salah satu cara untuk menghemat biaya pembelian alat scan tersebut adalah dengan menggunakan alat scan biasa yang telah terpasang pada printer. Kemudian hasil scan dengan menggunakan alat scan printer biasa tersebut diolah menggunakan algoritma sobel, sehingga nantinya akan 
didapatkan titik-titik yang memiliki piksel bewarna hitam sebagai jawaban pada LJK tersebut.

Algoritma sobel edge detection merupakan metode edge detection yang termasuk dalam gradient, edge detector. Piksel dari sebuah gambar yang dilakukan pendeteksian batas (edge) akan menjadi sebuah edge jika piksel tersebut melewati batas (threshold) tertentu. Pendeteksian batas (edge) dari sebuah gambar dilakukan dengan melakukan operasi matrik sobel terhadap gambar yang akan dilakukan pendeteksian gambar. (Murdianto, 2007).

\section{B. Rumusan Masalah}

Berdasarkan latar belakang dapat dirumuskan permasalah sebagai berikut:

Bagaimana membangun aplikasi pengolahan citra digital untuk pendeteksi jawaban pada lembar jawaban komputer menggunakan Algoritma sobel ?

\section{Batasan Masalah}

Batasan masalah dalam penelitaan ini sebagai berikut:

1. Pengolahan Citra Digital pada pendeteksian Lembar Jawaban Komputer menggunakan alat Scan biasa yang terpasang pada printer Canon MP-237.

2. LJK yang digunakan adalah LJK yang dicetak menggunakan aplikasi yang telah dibangun penulis.

3. LJK yang akan di-scan harus dalam keadaan baik, dan tidak rusak.

4. LJK yang akan di scan harus diletakkan secara rapi pada alat scan.

5. LJK yang digunakan merupakan LJK yang dibuat dari penulis.

6. Deteksi jawaban LJK yang terbaca pada salah satu pilihan jawaban yang diarsir, dan jawaban yang disilang tidak akan terdeteksi pada sistem.

\section{Tujuan Penelitian}

Tujuan yang ingin dicapai dalam penelitian ini adalah merancang dan membangun "Aplikasi Pengolahan Citra Pada Pendeteksi Lembar Jawaban Komputer menggunakan Algoritma Sobel"yang memiliki fungsi utama sebagai berikut :

1. Menghasilkan aplikasi yang dapat mendeteksi jawaban siswa pada lembar LJK.

2. Meminimalisir pengeluaran biaya untuk membeli alat scan yang khusus untuk memeriksa jawaban pada lembar LJK.

3. Sekolah dapat secara berkala menyelenggarakan Try Out pada siswanya.

4. Sekolah dapat menampilkan nilai ujian Try Out secara otomatis menggunakan report.

\section{E. Manfaat Penelitian}

Manfaat dari penelitian ini adalah:

1) Bagi penulis, dapat mengimplementasikan ilmu yang diperoleh selama di bangku perkuliahan.

2) Bagi pengguna perangkat lunak, dapat memberikan kemudahan dalam men-scan LJK tanpa harus membeli alat Scanner khusus.Aplikasi ini dapat digunakan untuk mendeteksi jawaban siswa pada LJK dan memeriksa kebenaran jawaban tersebut dan melatih siswa agar terbiasa mengisi LJK, sehingga tidak canggung lagi menghadapi ujian nasional.

\section{LANDASAN TEORI}

\section{A. Pengolahan Citra Digital}

Citra adalah gambar pada bidang dwimatra (dua dimensi. Ditinjau dari sudut pandang matematis, citra merupakan fungsi menerus (continue) dari intensitas cahaya pada bidang dwimatra. Sumber cahaya menerangi objek, objek memantulkan kembali sebagian dari berkas cahaya tersebut. Pantulan cahaya ini ditangkap oleh oleh alat-alat optik, misalnya mata pada manusia, kamera, pemindai (scanner), dan sebagainya, sehingga bayangan objek yang disebut citra tersebut terekam. Citra sebagai keluaran dari suatu sistem perekaman data memiliki sifat seperti dibawah ini :

1. optik berupa foto,

2. analog berupa sinyal video seperti gambar pada monitor televisi,

3. digital yang dapat langsung disimpan pada suatu pita magnetik.

Meskipun sebuah citra kaya informasi, namun seringkali citra yang kita miliki mengalami penurunan mutu (degradasi), misalnya mengandung cacat atau derau (noise), warnanya terlalu kontras, kurang tajam, kabur (blurring), dan sebagainya. Agar citra yang mengalami gangguan mudah diinterpretasi baik oleh manusia maupun mesin, maka citra tersebut perlu dimanipulasi menjadi citra lain yang kualitasnya lebih baik. Bidang studi yang menyangkut hal ini adalah pengolahan citra (Muthukrishnan dkk, 2011).

Pengolahan citra adalah pemrosesan citra, khususnya dengan menggunakan komputer, menjadi citra yang kualitasnya lebih baik. Umumnya, operasioperasi pada pengolahan citra diterapkan pada citra bila perbaikan atau memodifikasi citra (Parkesit, 2008).

\section{B. Deteksi Tepi}

Deteksi tepi pada suatu citra adalah suatu proses yang menghasilkan tepi-tepi dari obyek-obyek citra, tujuannya adalah :

1. Untuk menandai bagian yang menjadi detail citra 
2.Untuk memperbaiki detail dari citra yang kabur, yang terjadi karena error atau adanya efek dari proses akuisisi citra.

\section{Algoritma Sobel}

Metode Sobel merupakan pengembangan metode Robert dengan menggunakan filter HPF (High Pass Filter) yang diberi satu angka nol penyangga. Kelebihan dari metode Sobel ini adalah kemampuan untuk mengurangi noise sebelum melakukan perhitungan deteksi tepi.

Operator ini menggunakan dua $3 \times 3$ kernels yang dikonvolusi dengan citra asli untuk menghitung tafsiran dari derivatif pertama untuk perubahan horizontal dan satu untuk vertikal. Jika kita mendefinisikan A sebagai citra sumber dan $G_{x} \& G_{y}$ adalah dua citra yang tiap pada pointnya berisi tafsiran derivatif vertikal dan horizontal.

\begin{tabular}{|c|c|c|c|c|c|}
\hline-1 & 0 & +1 & +1 & +2 & +1 \\
\hline-2 & 0 & +2 & 0 & 0 & 0 \\
\hline-1 & 0 & +1 & -1 & -2 & -1 \\
\hline \multicolumn{3}{|c|}{$G x$} & \multicolumn{3}{|c|}{ Gy } \\
\hline
\end{tabular}

Gambar 2.4 Mask Sobel

Pada gambar diatas merupakan sepasang matrik sobel yang digunakan untuk mendeteksi batas dari sebuah gambar. Untuk melakukan deteksi batas gambar (edge), dilakukan dengan melakukan perkalian terhadap matriks tersebut secara terpisah. Matriks Gx berfungsi untuk memrperkirakan gradient pada sumbu $\mathrm{x}$, sedangkan matrik Gy berfungsi untuk memperkirakan gradient pada sumbu y.

$\mathrm{G}_{\mathrm{x}}=\left[\begin{array}{ccc}+1 & 0 & -1 \\ +2 & 0 & -2 \\ +1 & 0 & -1\end{array}\right] * \mathrm{~A} \quad$ dan $\mathrm{G}_{\mathrm{y}}=\left[\begin{array}{ccc}+1 & +2 & +1 \\ 0 & 0 & 0 \\ -1 & -2 & -1\end{array}\right] * \mathrm{~A}$

\section{Model Pengembangan Waterfall}

Model ini mengusulkan sebuah pendekatan kepada perkembangan software yang sistematik dan sekuensial yang mulai pada tingkat dan kemajuan sistem pada seluruh analisis, desain, kode, pengujian, dan pemeliharaan (Pressman, 2002).

\section{E. Unified Modelling Language}

Model perangkat lunak dapat dianalogikan seperti pembuatan blueprint pada pembangunan gedung. Menurut Huda dan Nugroho (2010:137), UML adalah sebuah bahasa yang telah menjadi standar dalam industri untuk visualisasi, merancang, dan mendokumentasikan sistem perangkat lunak. UML versi 2.0 tersebut terdiri dari empat belas teknik diagram, seperti yang dinyatakan oleh Dennis et al. (2005:30):

The Version 2.0 of the UML defines a set of fourteen diagramming techniques used to model a system. The diagrams are broken into two major groupings: one for modeling structure of a system and one for modeling behavior. The structure modeling diagrams include class, object, package, deployment, component, and composite structure diagrams. The behavior modeling diagrams include activity, sequence, communication, interaction overview,behavior state machine, protocol state machine, and use case diagrams.

Berdasarkanpernyataan Dennis et al. tersebut, UML versi 2.0 mendefinisikanempatbelasdiagram UML yang dapatdi gunakan untuk memodelkan suatu sistem. Diagram yang digunakan dibagi menjadi dua kelompok utama: satu untuk pemodelan struktur suatu sistem dan satu lagi untuk pemodelan sifat suatu sistem. structure diagrams terdiri dari class diagram, object diagram, package diagram, deployment diagram, component diagram, dan composite structure diagram. Sedangkan behavior diagrams terdiri dari activity diagram, sequence diagram, communication diagram, interaction overview diagram, behavior state machine diagram, protocol state machine diagram, danuse case diagram.

\section{F. Delphi}

Delphi merupakan sebuah program berbasiskan windows yang memiliki bahasa mirip dengan pascal. Jadi bila anda telah menguasai pascal barangkali tidak akan kesulitan dalam menggunakan program ini. Perbedaan mendasar antara Delphi dengan pascal adalah bahwa delphi memiliki oop (object orientation program) atau program yang berorientasikeobjek.

Dengan demikian Delphi lebih mudah digunakan dibandingkan dengan pascal, karena anda hanya tinggal mengatur properti atau sifat dari objek dan menambahkan sedikit pengkodean.

\section{G. Basis Data}

Menurut Khadir (2008) Basis Data merupakan file yang berisikan tabel-tabel yang saling berinteraksi sehingga dapat diproses dan digunakan dengan cepat dan mudah. Tabel merupakan kumpulan data yang tersusun menurut aturan tertentu dan berhubungan dengan topik tertentu.

Tabel diorganisasikan dalam dua bagian, bagian menurun atau kolom disebut dengan field dan bagian mendatar atau baris disebut dengan record.

\section{Metodologi Penelitian}

\section{A. Metode Pengumpulan Data}

Adapun teknik pengumpulan data yang digunakan dalam peneltian ini antara lain:

1. StudiPustaka 


\section{Observasi}

\section{B. Metode Pengembangan Sistem}

Pengembangan Aplikasi Pengolahan Citra Pada

Pendeteksi Lembar Jawaban Komputer dalam Tugas Akhir ini menggunakan model waterfall. Adapun langkah-langkah yang dilakukan dalam pengembangan sistem sebagai berikut:

\section{Initial Investigation (penelitianawal)}

Penelitian awal dilakukan dengan mempelajari berbagai referensi sehingga didapat rumusan masalah, batasan, dantujuan yang akan digunakan untuk membangun dan mengembangkan sistem.

2. Requirements Definition (definisikebutuhan)

Pada tahap ini dilakukan pendefinisian kebutuha perangkat keras (hardware) dan kebutuhan perangkat lunak (software).

3. System Design (perancangansistem)

Perancangan sistem meliputi perancangan database, pemodelan perangkat lunak menggunakan UML dan perancangan antarmuka perangkat lunak.

4. Coding and Testing (pengkodean dan pengujian)

a. Pengkodean perangkat lunak menggunakan bahasa pemrograman Pascal dengan editor Delphi dan pengkodean database menggunakan SQL Server 2008.

b. Pengujianmenggunakan Black Box testing, yang meliputi :

1. Validasi, dilakukan pengujian terhadap kebenaran hasil deteksi Jawaban dari LJK.

2. Desain tes, dilakukan dengan cara pengujian individual untuk melihat apakah desain yang dihasilkan berfungsi sesuai dengan perancangan.

3. Interface, dilakukan dengan mengoperasikan perangkat lunak.

4. Database, dilakukan dengan cara mengakses database, apakah berhasil diakses atau tidak.

5. Analisa kinerja system.

6. Operation and Support (pengoperasian dan dukungan)

a. Pengoperasiansistem dilakukan oleh guru SMPN 2 Kota Bengkulu dan kepala kurikulum.

b. Support ataud ukungan agar aplikasi bisa digunakan dalam waktu panjang adalah dengan melakukan pemeliharaan dan pengembangan.

\section{PERANCANGAN SISTEM}

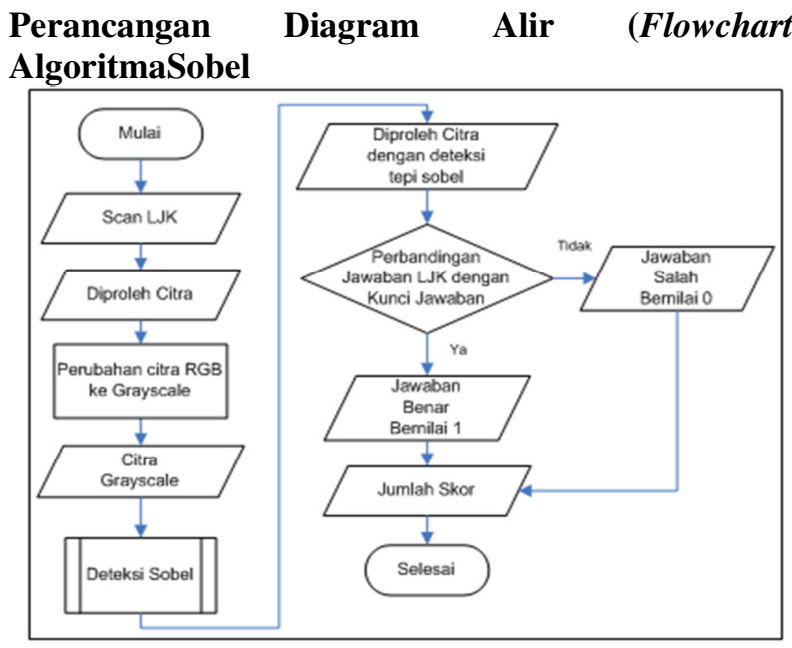

Gambar 4.1 Flowchart AlgoritmaSobel

\section{Perancangan UML}

\section{Use Case Diagram}

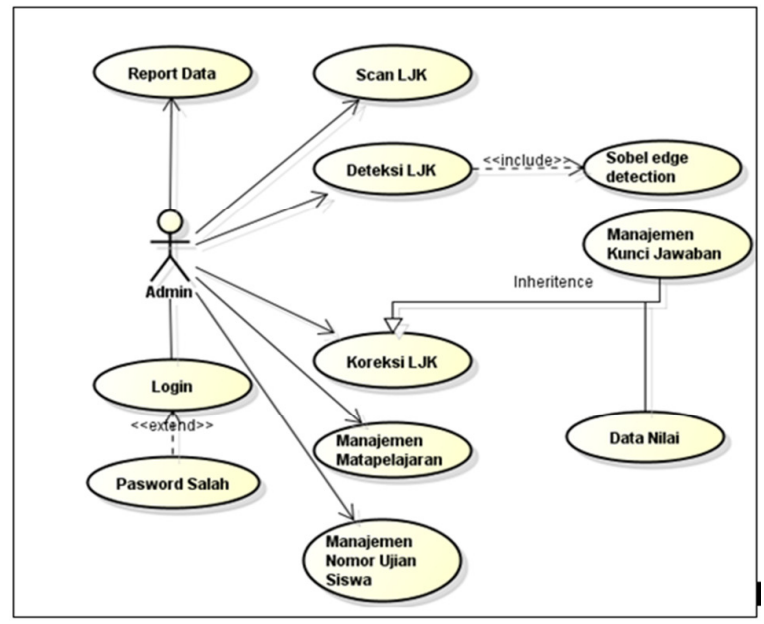

Gambar4.2Use CaseDiagram

\section{Class Diagram}

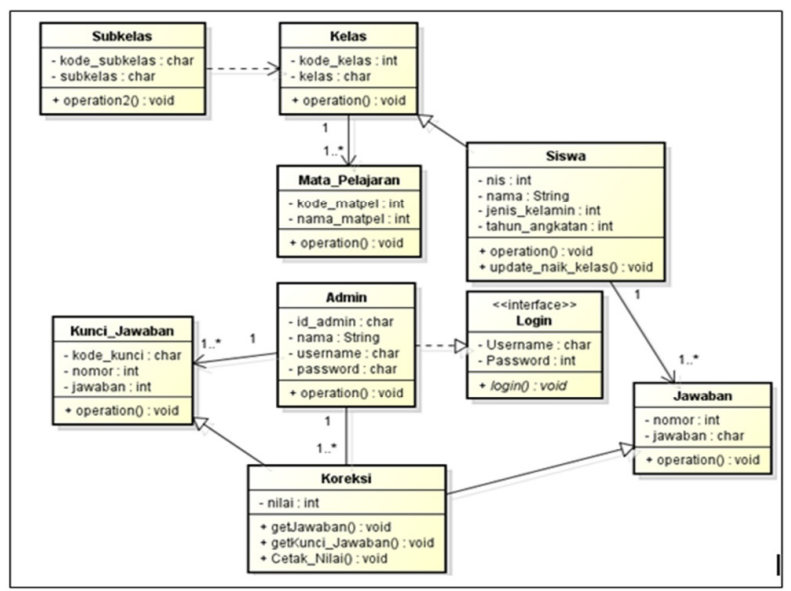

Gambar 4.3Class Diagram 


\section{Perancangan Table Relationship}

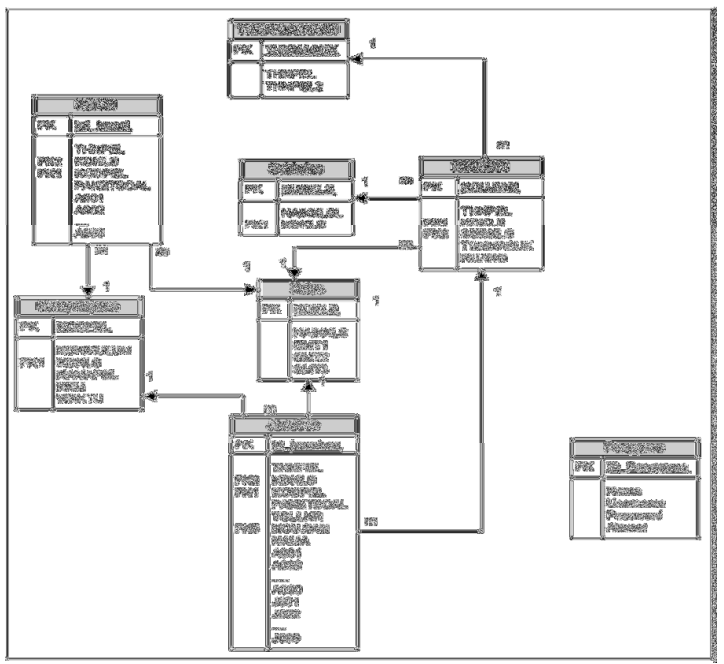

Gambar 4.4Table Relationship Diagram

\section{HASIL DAN PEMBAHASAN}

\section{Hasil Implementasi}

1. Form Utama

Pada Form Utama ini terdapat banyak menu-menu Form yang terhubung. Form yang terhubung diantaranya yaitu Form Mata pelajaran, Form Nomor Ujian, Form Kunci Jawaban, Form Koreksi LJK dan Form Report. Berikut ini merupakan Form Utama pada gambar 5.1 saat Aplikasi dibuka.

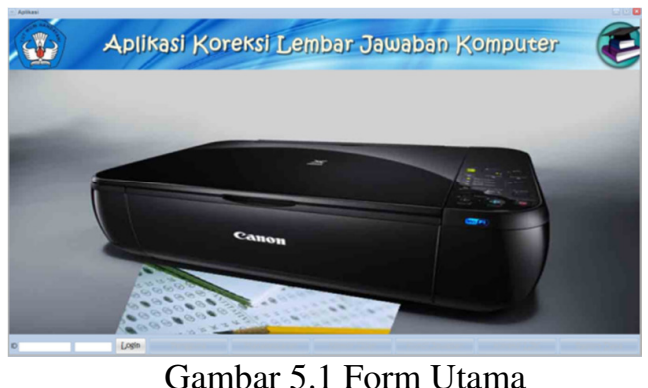

Pada gambar 5.1 ini merupakan Form Utama yang digunakan mengoprasikan sistem yang ada pada menu Form yang tersedia. Namun sebelum admin mengoprasikan sistem. Admin terlebih dahulu harus melakukan login dengan menginput Id username dan password.

\section{Form Koreksi}

user melakukan-scan LJK di scan printer dengan mengklik tombol Scan LJK. Maka citra Lembar Jawaban Komputer akan tampil ke dalam area picture seperti pada gambar 5.2 dengan waktu scanning6,57 detik.

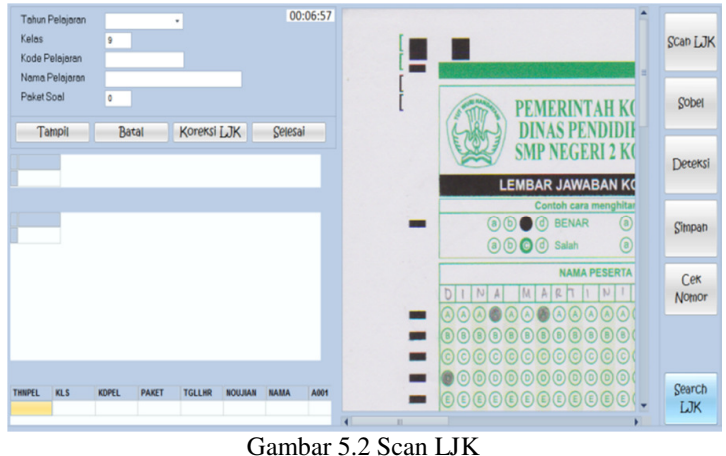

Setelah dilakukan scan LJK, maka image tersebut harus dirubah kedalam bentuk deteksi tepi Sobel dengan menglik tombol sobel. Maka akan tampil seperti gambar 5.3 dengan durasi 1,48 detik.

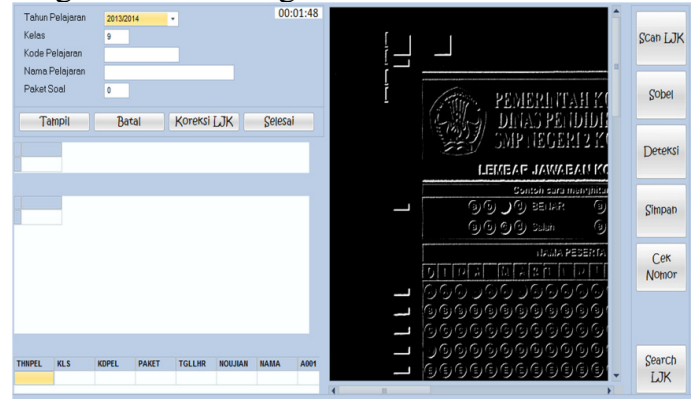

Gambar 5.3Deteksi Tepi Sobel

Setelah citra LJK dirubah kedalam bentuk deteksi tepi sobel maka kita akan mendapatkan ekstraksi untuk mendeteksi nomor ujian, nama, tanggal lahir, nama, kode pelajaran, paket soal, dan jawaban pada LJK. Pada gambar 5.4 merupakan gambar Deteksi LJK dengan durasi 1,78 detik

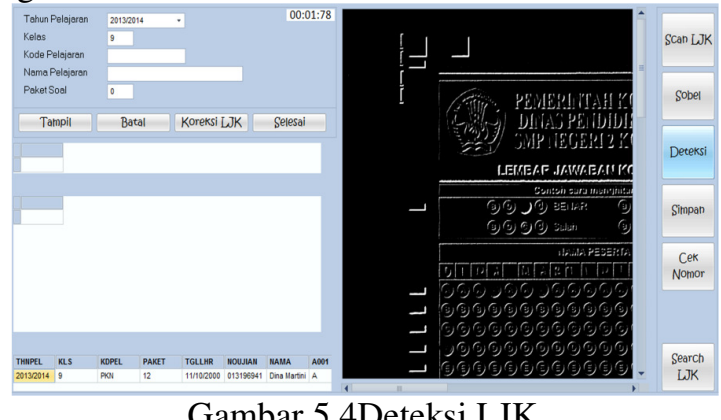

Gambar 5.4Deteksi LJK

Dari gambar 5.4 dapat diperjelas kembali dengan melihat hasil pengujian deteksi LJK pada gambar 5.5 dan 5.6 dibawah ini. 


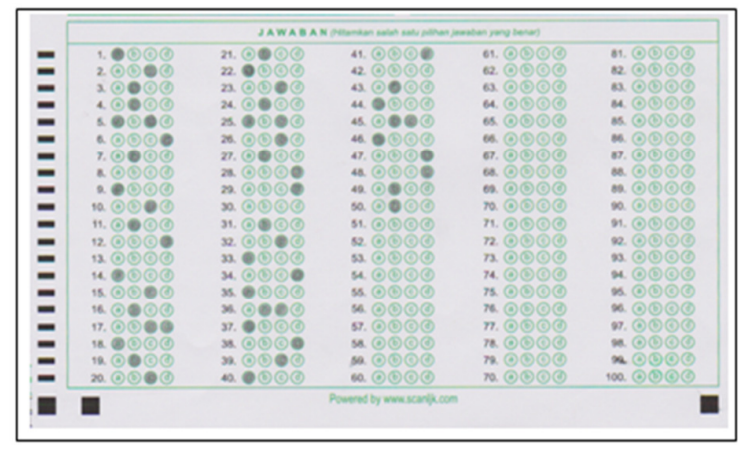

Gambar 5.5LJK dengan nomor ujian 013196941

\begin{tabular}{|c|c|c|c|c|c|c|c|}
\hline THNPEL & KLS & KOPEL & PAKET & TGLLHR & MOUJIAN & MAMA & A001 \\
\hline $2013 / 2014$ & 9 & PKN & 12 & $11 / 10 / 2000$ & 013196941 & Dina Marthi & A \\
\hline A001 & A002 & A003 & A004 & A005 & A006 & A007 & A008 \\
\hline A & c & B & B & & D & B & \\
\hline \multirow[t]{2}{*}{ A008 } & A009 & A010 & A011 & A012 & A013 & A014 & A015 \\
\hline & A & c & B & 0 & & A & c \\
\hline A015 & A016 & A017 & A018 & A019 & A020 & A021 & A022 \\
\hline c & B & & A & B & c & 8 & A \\
\hline A022 & A023 & A024 & A025 & A026 & A027 & A028 & A029 \\
\hline A & c & 8 & & c & B & D & D \\
\hline A029 & A030 & A031 & A032 & A033 & A034 & A035 & A036 \\
\hline D & & 8 & c & A & D & A & \\
\hline \multirow[t]{2}{*}{ A036 } & A037 & A038 & A039 & A040 & A041 & A042 & A043 \\
\hline & A & D & c & A & D & & $B$ \\
\hline A043 & A044 & A045 & A046 & A047 & A048 & A049 & A050 \\
\hline B & A & & A & D & D & B & B \\
\hline
\end{tabular}

Gambar 5.6 Deteksi Jawaban

Dari gambar 5.5 dan 5.6 maka dapat disimpulkan bahwa jawaban pada lembar jawaban komputer $(L J K)$ yang tidak dilingkari maupun jawaban yang dilingkari lebih dari 1 (gambar 5.5) maka hasil deteksi LJK akan kosong (gambar 5.6).

Setelah semua LJK di scan dan hasil deteksi masing-masing LJK disimpan ke database, pengguna dapat melakukan pengoreksian seluruh data LJK siswa.

Pengguna harus terlebih dahulu menginputkan data tahun pelajaran, kelas, kode pelajaran dan paket soal dan klik tampil maka akan muncul data kunci jawaban dan data jawaban pada seluruh LJK seperti pada gambar 5.7.

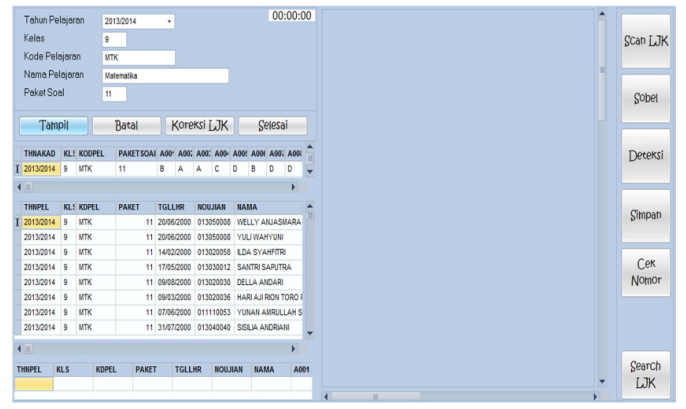

Gambar 5.7 Input Data Untuk Tampil Data Kunci dan Jawaban
Dari gambar 5.7 pengguna dapat melakukan koreksi pada semua data LJK dengan menekan tombol koreksi. Hasil koreksi dan waktu koreksi tampil seperti gambar 5.8 berikut.

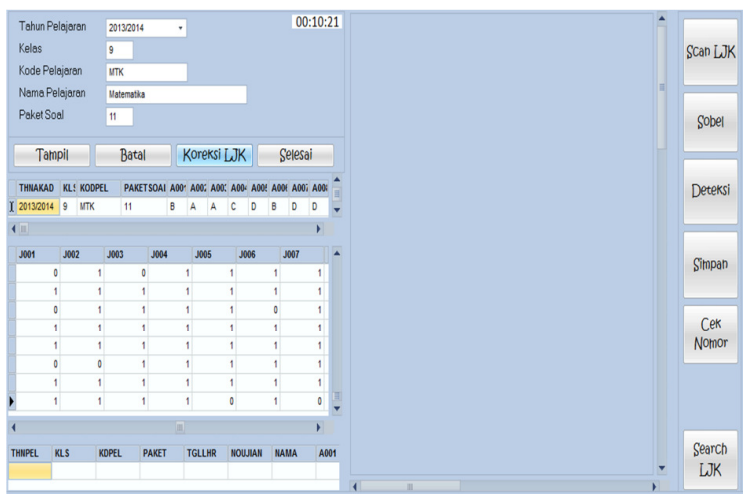

Gambar 5.8 Skor Nilai Hasil Koreksi

Dari gambar 5.8 waktu koreksi untuk semua data LJK yaitu 10,21 detik dan skor hasil koreksi merupakan skor penilaian. Sistem membandingkan data kunci jawaban dengan data jawaban siswa.

Jika data jawaban sama dengan data kunci jawaban maka skor nilai 1 , sebaliknya jika data tidak sama maka skor nilai 0 . Jumlah nilai diperoleh dengan penjumlahan semua skor nilai.

Sedangkan nilai akhir merupakan hasil perhitungan dari jumlah nilai dibagi dengan banyaknya field yang terisi pada data kunci jawaban. Kemudian jumlah nilai dan nilai akhir akan diperoleh dari skor nilai seperti gambar 5.9.

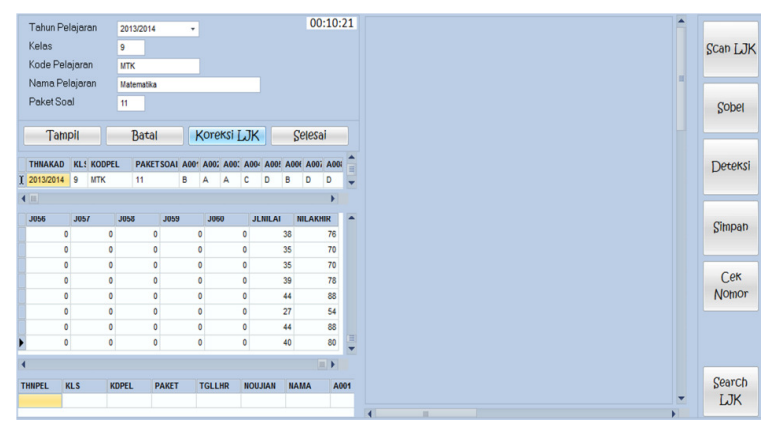

Gambar 5.9 Jumlah Nilai dan Nilai Akhir

\section{Form Report}

Form ini merupakan Form untuk mencetak semua laporan, sehingga menghasilkan laporan yang dinamis yang dapat di cetak sesuai dengan nilai parameter yang ditentukan. 


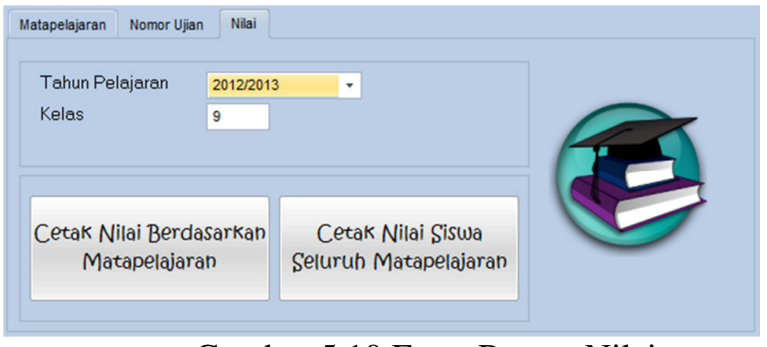

Gambar 5.10 Form Report Nilai

Gambar 5.10 form report nilai siswa dicetak menggunakan input paramater karena mencetak semua data nilai berdasarkan group by Tahun Pelajaran, dan Kelas seperti hasil cetak report pada gambar 5.11 cetak nilai berdasarkan matapelajaran.

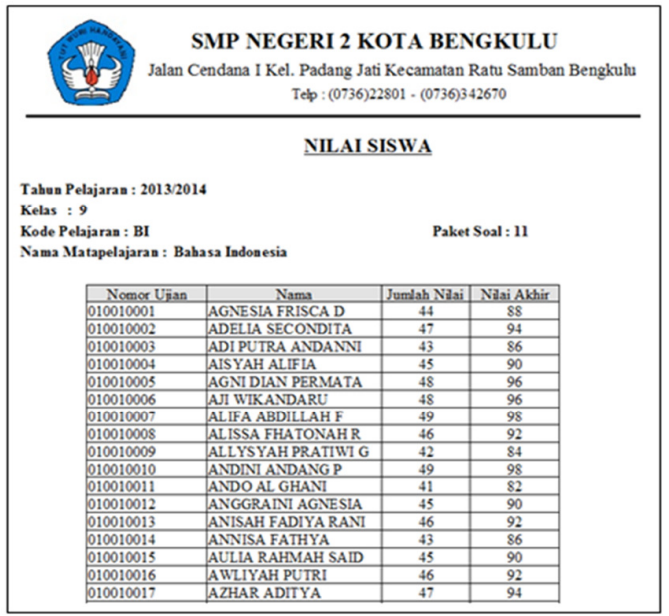

Gambar 5.11 Cetak Nilai Berdasarkan Matapelajaran

Selain cetak nilai berdasarkan matapelajaran, report nilai juga menampilkan cetak nilai siswa seluruh matapelajaran dengan menginput parameter berupa tahun pelajaran dan kelas pada gambar 5.12.

Pada gambar 5.43 matapelajaran B.I, MTK, BING memiliki nilai untuk setiap masing-masing siswa akan tetapi untuk matapelajaran lainnya memiliki nilai nol dikarenakan pada matapelajaran tersebut belum dikoreksi. Pada source code sudah dijelaskan bahwa:

"SELECT a.thnpel, a.noujian, a.nama, a.kls,

SUM (CASE a.kdpel when "MTK" THEN a.nilakhir ELSE 0 END) AS matematika"

Penjelasan pada potongan coding $S Q L$ tersebut bahwa menampilkan semua data nilai akhir berdasarkan kode matapelajaran "Matematika" untuk setiap tahun pelajaran, nomor ujian, nama dan kelas, jika nilai pada matapelajaran tersebut tidak ada maka akan ditampilkan nilai "nol", begitu juga untuk nilai pada matepelajaran yang lain. Nilai untuk setiap siswa ditampilkan berdasarkan tahun pelajaran dan kelas pada form report menggunakan "group by" pada desain report.

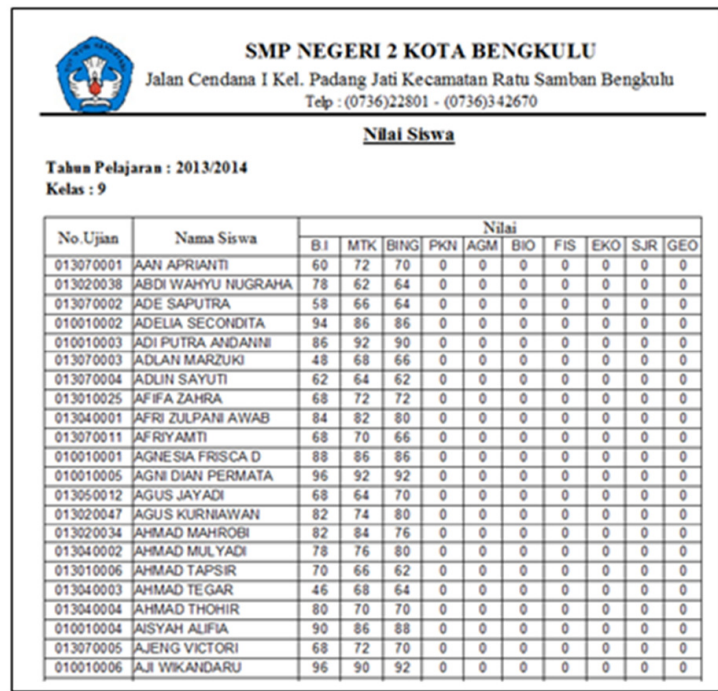

Gambar 5.12 Cetak Nilai Siswa Seluruh Matapelajaran

\subsection{Pengujian Waktu}

Pengujian ini dilakukan untuk membuktikan kesesuaian waktu pada rancangan model sequence diagram dengan waktu sebenarnya. Pengujian menggunakan pengukur waktu timer, laptop Compaq 510, printer scanner MP230. Pada proses ini, waktu yang dihitung adalah waktu yang dibutuhkan untuk melakukan proses Scan LJK, Sobel, Deteksi Jawaban, Simpan Hasil Deteksi, Koreksi Per LJK dan Koreksi 314 LJK. Waktu mulai dihitung ketika menekan tombol scan, sobel, deteksi jawaban, simpan, dan koreksi sampai muncul pemberitahuan berhasil.

Rata-rata waktu yang dibutuhkan untuk melakukan Scan LJK adalah 6,29 detik, Sobel 1,528 detik, Deteksi Jawaban 1,812 detik, Simpan Hasil Deteksi 1,858 detik, Koreksi per LJK 0,537 detik dan Koreksi 314 LJK 10,25 detik. Rata-rata waktu tersebut diperoleh dari data Lampiran F pada halaman F-2.

\section{KESIMPULAN DAN SARAN}

\section{A. Kesimpulan}

Berdasarkan hasil pembahasan, maka secara umum diambil kesimpulan bahwa:

1. Aplikasi pengolahan citra digital dalam melakukan koreksi pada lembar Jawaban Komputer ini dirancang dan dibangun dengan menggunakan algoritma sobel yang dapat menghasilkan hasil deteksi LJK dari deteksi tepi pada sebuah citra LJK.

2. Hasil deteksi LJK yang terbaca berupa arsiran pada salah satu pilihan jawaban dan hasil deteksi LJK yang tidak dapat terdeteksi berupa arsiran lebih dari satu pilihan jawaban atau dilakukan dengan penyilangan pada pilihan jawaban tersebut.

3. Aplikasi ini di lengkapi dengan menu pencetak laporan otomatis atau report. Menu report yang 
ditampilkan yaitu kartu ujian siswa, matapelajaran dan nilai siswa.

4. Hasil pengujian rata-rata waktu dalammelakukan Scan LJK adalah 6,29 detik, Sobel 1,528 detik, Deteksi Jawaban 1,812 detik, Simpan Hasil Deteksi 1,858 detik, Koreksi per LJK 0,537 detik dan Koreksi 314 LJK 10,25 detik.

\section{B. Saran}

Berdasarkan hasil pembahasan yang telah diuraikan, saran dari penelitian berikutnya yaitu:

1. Aplikasi yang dibangun untuk pemeriksaan LJK bekerja dengan baik menggunakan printer scanner, untuk penelitian selanjutnya mungkin dapat dikembangkan dengan pembacaan hasil deteksi LJK berupa penyilangan menggunakan pensil maupun menggunakan pulpen. Pengembangan aplikasi ini dapat menggunakan metode yang lebih baik lagi.

2. Untuk penelitian selanjutnya aplikasi yang dibangun dapat menggunakan perangkat keras scanner yang berbeda, untuk melakukan deteksi LJK secara sekaligus, agar lebih menghemat waktu dalam memperoleh hasil deteksi LJK.

\section{DAfTAR PUStaka}

[1] Dennis et al. 2005. System Analysis and Design with uml version 2.0.United States of Americ: A Wiley-Interscience Publication.

[2] Huda, MiftakhuldanBunafitNugroho.2010. MembuatAplikasi Database dengan Java, MySQL, dan NetBeans.Jakarta : PT. Elex Media Komputindo.

[3] Kadir, Abdul.2008. Belajar Database MenggunakanSql Server.Yogyakarta : Penerbit Andi.

[4] Murdianto, Arie.2007. Ekstraksi Fitur Wajah. Fakultas Ilmu Komputer Universitas Indonesia: JurnalDiterbitkan.

[5] Nugroho, Andi. 2005, Rasional Rose untukPemodelanBerorientasiObjek, Bandung: PenerbitInformatika

[6] Parkesit, Dian. 2010. Analisis Deteksi Tepi Untuk Mengidentifikasi Pola Wajah Review (Image Edge Detection Based and Morphology).Magister komputer Universitas Budi Luhur Jakarta:Thesis Diterbitkan.

[7] Pressman, Roger S. 2002, Rekayasa Perangkat Lunak Pendekatan Praktisi (BukuSatu), Yogyakarta: Penerbit Andi 